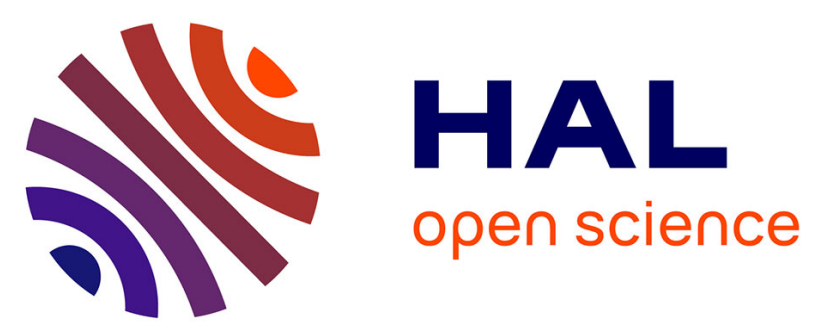

\title{
Maghemite nanoparticles and maghemite/silica nanocomposite microspheres as magnetic Fenton catalysts for the removal of water pollutants
}

Nassira Ferroudj, Jimmy Nzimoto, Anne Davidson, Delphine Talbot, Emmanuel Briot, Vincent Dupuis, Agnès Bée, Mohamed Salah Medjram, Sébastien Abramson

\section{To cite this version:}

Nassira Ferroudj, Jimmy Nzimoto, Anne Davidson, Delphine Talbot, Emmanuel Briot, et al.. Maghemite nanoparticles and maghemite/silica nanocomposite microspheres as magnetic Fenton catalysts for the removal of water pollutants. Applied Catalysis B: Environmental, 2013, 136-137, pp.9-18. 10.1016/j.apcatb.2013.01.046 . hal-01525868

\section{HAL Id: hal-01525868 \\ https://hal.sorbonne-universite.fr/hal-01525868}

Submitted on 23 May 2017

HAL is a multi-disciplinary open access archive for the deposit and dissemination of scientific research documents, whether they are published or not. The documents may come from teaching and research institutions in France or abroad, or from public or private research centers.
L'archive ouverte pluridisciplinaire HAL, est destinée au dépôt et à la diffusion de documents scientifiques de niveau recherche, publiés ou non, émanant des établissements d'enseignement et de recherche français ou étrangers, des laboratoires publics ou privés. 


\title{
Maghemite nanoparticles and maghemite/silica nanocomposite
}

\section{microspheres as magnetic Fenton catalysts for the removal of water pollutants}

\author{
Nassira Ferroudj ${ }^{\mathrm{a}, \mathrm{b}}$, Jimmy Nzimoto ${ }^{\mathrm{a}}$, Anne Davidson ${ }^{\mathrm{c}}$, Delphine Talbot ${ }^{\mathrm{a}}$, Emmanuel \\ Briot $^{\mathrm{a}}$, Vincent Dupuis ${ }^{\mathrm{a}}$, Agnès Bée ${ }^{\mathrm{a}}$, Mohamed Salah Medjram ${ }^{\mathrm{b}}$, Sébastien Abramson ${ }^{\mathrm{a} * *}$ \\ ${ }^{a}$ Laboratoire de Physicochimie des Electrolytes, Collö̈des et Sciences Analytiques (PECSA-UMR 7195 UPMC- \\ CNRS-ESPCI) UPMC, 4 Place Jussieu, 75252 Paris Cedex 5, France \\ ${ }^{b}$ Laboratoire de Génie Chimique et Environnement de Skikda, Université du 20 Août 1955 de Skikda, BP 26 \\ Route d'El Hadaiek, Skikda, Algérie \\ ${ }^{c}$ Laboratoire de Réactivité de Surface (LRS-UMR 7197 UPMC-CNRS), UPMC, 3 rue Galilée, 94200 \\ Ivry/Seine, France \\ * corresponding author: sebastien.abramson@upmc.fr ; Tel: +33144273174 ; Fax : + 33144273228
}




\begin{abstract}
Maghemite nanoparticles $\left(\gamma-\mathrm{Fe}_{2} \mathrm{O}_{3} \mathrm{NP}\right)$, and maghemite/silica nanocomposite microspheres $\left(\gamma-\mathrm{Fe}_{2} \mathrm{O}_{3} / \mathrm{SiO}_{2} \mathrm{MS}\right)$, have been evaluated as magnetic heterogeneous Fenton catalysts. The catalysts were fully characterized by electronic microscopies, magnetometry, XRD, UV-VisNIR spectroscopy, and sorption volumetry. It was found that the two materials differ in size, morphology, porosity and microstructure, although the maghemite nanoparticles are not modified by their encapsulation into the silica. Both catalysts have a strong magnetic susceptibility, but only the MS catalyst can be easily recovered by magnetic settlement. The mineralization and decolorization of aqueous solutions containing a model pollutant in presence of the catalysts were comparatively studied. Three model pollutants differing in their structure and their electrostatic charge were tested. The obtained reaction rates depend on the nature of the pollutant and catalyst. The results indicate the existence of a correlation between the amount of adsorbed pollutant and the decolorization rate. The free NP are usually more active than the MS catalyst, but larger velocity can also be obtained with the MS catalyst when the pollutant is strongly adsorbed on this material. Moderate mineralization rates were observed for both catalysts illustrating the larger stability toward oxidation of the uncoloured organic intermediates resulting from the primary degradation of the model pollutants. Moreover the efficiency and stability of the MS catalyst were established since this material showed an activity for a pollutant during five consecutive tests. This was also confirmed by characterization of the catalyst after these tests.
\end{abstract}

\title{
Keywords
}

Iron Oxide Nanoparticles, Silica Microspheres, Magnetic Nanocomposites, Fenton Catalyst, Water-Treatment 


\section{1- Introduction}

The increasing contamination of surface and ground waters by a wide variety of inorganic and organic pollutants is one of the major challenges faced by humanity at the beginning of the $21^{\text {th }}$ century.[1] The development of agriculture, industry, and domestical activities is the major cause for the emissions of these pollutants which tend to accumulate in the trophic chain, having a detrimental impact on ecosystems and human health [2]. Wastewater and drinking water treatment can reduce this concern, but the existing methods suffer from several drawbacks such as incomplete pollutant removal, high-energy requirements, or production of toxic sludges and other waste products that require further treatment. In this context, there is a real need for more powerful methods to decontaminate drinking water and domestic or industrial wastewaters.[3-5]

The efficiency and simplicity of advanced oxidation processes (AOP) make them suitable candidates for the removal of toxic organic chemicals from wastewater, in replacement or in addition to the usual techniques. These processes have in common to generate hydroxyl (HO•) radicals which are characterized by a very high standard potential $\left(\mathrm{E}_{0}=2.7 \mathrm{~V}\right)$ allowing the mineralization of numerous classes of organic pollutants.[6] The goal of the wastewater purification by means of AOP procedures is the removal of the chemical contaminants to such an extent that the cleaned wastewater may be reintroduced into the environment or, at least, into a conventional process flow. The so-called Fenton-like reactions, which derive from the researches of H. J. H. Fenton more than 100 years ago, are among the most studied AOP. [7] In that case, the $\mathrm{HO} \bullet$ is generated from decomposition of hydrogen peroxide in presence of a catalyst, which can possibly be activated by light, ultrasounds or electricity. Although homogeneous catalysts such as soluble ferrous $\left(\mathrm{Fe}^{2+}\right)$ ions have been traditionally used, heterogeneous Fenton catalysts have been recently developed. [8-11] Although high reaction rates are generally obtained with homogeneous catalysts, the necessity to work in acidic $\mathrm{pH}$, 
the difficulty of the separation of the catalyst from the effluent which leads to generation of iron oxide sludges, limit their use in water-treatment. On the contrary, heterogeneous Fenton catalysts can be recovered and they are still active at $\mathrm{pH}$ near neutrality. $[8,10]$ Moreover in comparison to other heterogeneous catalysts used in AOP such as nano- $\mathrm{TiO}_{2}$, these catalysts present a low toxicity and they can work in absence of light. Two main categories of materials have been tested in Fenton-type reactions. The first one is composed of materials containing individual iron species, such as $\mathrm{Fe}^{2+}$ or $\mathrm{Fe}^{3+}$ exchanged zeolithes or clays.[8-10] The second category is composed of materials containing iron oxide particles or nanoparticles, used in pure form or dispersed on a support.[9,11] Good catalytic activities were generally obtained with both types of materials but some drawbacks are still encountered such as Fe-leaching, and difficulty of the recovery of the catalyst. [10]

The use of magnetic divided materials as adsorbents or heterogeneous catalysts in water cleanup has attracted increasing attention [12-14]. Indeed these materials, which usually contain an iron oxide phase such as magnetite $\left(\mathrm{Fe}_{3} \mathrm{O}_{4}\right)$, maghemite $\left(\gamma-\mathrm{Fe}_{2} \mathrm{O}_{3}\right)$ or ferrite $\left(\mathrm{MFe}_{2} \mathrm{O}_{4}\right.$, with $\left.\mathrm{M}=\mathrm{Ba}, \mathrm{Co}, \mathrm{Mn} ..\right)$, can be easily removed from water by the simple use of a magnetic field gradient obtained with a magnet or an electromagnet. Magnetic settlement can be faster and more efficient than filtration and decantation, the traditional separation methods used in water-treatment.[14] Moreover magnetic particles can be applied in more complex processes such as magnetic fluidized beds. $[12,15]$ At industrial scale, the Sirofloc $®$ process is a good illustration of the potential of magnetic materials in sewage or drinking water plants. [16] As attested by recent reviews on this subject, magnetic adsorbents are much more studied than magnetic catalysts. $[13,14]$ Nevertheless, magnetic materials have been tested as catalysts in dechlorination reactions[15] and in various AOP such as photocatalysis,[17] catalytic ozonation,[18] non-thermal plasma processes,[19] and Fenton-type reactions. [9,11,20-33] Magnetically separable iron oxide particles of various sizes and origins were 
thus used as Fenton catalysts on several model pollutants. [20-28] More recently, iron oxide magnetic nanoparticles encapsulated in polymer shells [29], carbonaceous materials [30,31] or mesoporous silicas [32,33] have been tested as catalysts in Fenton-like reactions. Although good catalytic activities were obtained, concomitant with a facile magnetic settlement of the catalyst, any of these works clearly showed the influence of the dispersion of small magnetic nanoparticles in a porous matrix on their catalytic activity and their ability to be recovered. Here we present the characterization and use of two magnetic heterogeneous Fenton catalysts, maghemite nanoparticles $\left(\gamma-\mathrm{Fe}_{2} \mathrm{O}_{3} \mathrm{NP}\right)$, and maghemite/silica nanocomposite microspheres $\left(\gamma-\mathrm{Fe}_{2} \mathrm{O}_{3} / \mathrm{SiO}_{2} \mathrm{MS}\right)$. The aim of this paper is to study how the encapsulation of the magnetic nanoparticles into the silica beads influences their catalytic activity, their stability and their separation properties. Small dispersed nanoparticles should be highly active, but their colloidal stability may prevent their separation from the effluent, even using magnetic settlement. Their encapsulation in a porous microsized support may facilitate their separation, but, at the same time, diffusion of the pollutants up to the catalytic sites may be slowed down. All these parameters may be also influenced by the nature of the pollutants. Therefore, we tested the catalytic activity of the materials on three aqueous model pollutants, methylene blue (MB), methylorange (MO) and paranitrophenol (PNP), each of them characterized by a different structure and electrostatic charge (see figure 1). Finally, to evaluate the practicality of these catalysts in water treatment, we present our attempts to recover and reuse these materials, and to characterize them after several catalytic tests. 


\section{2- Experimental part}

\subsection{Syntheses}

\subsubsection{Synthesis of the maghemite nanoparticles $\left(\gamma-\mathrm{Fe}_{2} \mathrm{O}_{3} \mathrm{NP}\right)$}

The $\gamma-\mathrm{Fe}_{2} \mathrm{O}_{3}$ NP used in this study were synthesized according to a procedure described elsewhere [34-36]. Briefly, magnetite $\left(\mathrm{Fe}_{3} \mathrm{O}_{4}\right)$ nanoparticles were first prepared by the Massart's method, adding ammonia to an aqueous mixture of $\mathrm{FeCl}_{3}$ and $\mathrm{FeCl}_{2}$ [34]. Then, the $\mathrm{Fe}_{3} \mathrm{O}_{4}$ nanoparticles were oxidized to $\gamma-\mathrm{Fe}_{2} \mathrm{O}_{3}$ by successively adding $\mathrm{HNO}_{3}$ and $\mathrm{Fe}\left(\mathrm{NO}_{3}\right)_{3}$ [35-36]. The $\gamma-\mathrm{Fe}_{2} \mathrm{O}_{3} \mathrm{NP}$ were finally obtained as an aqueous acidic dispersion with a high colloidal stability also called ferrofluid.

\subsubsection{Synthesis of the maghemite/silica microspheres $\left(\gamma-\mathrm{Fe}_{2} \mathrm{O}_{3} / \mathrm{SiO}_{2} \mathrm{MS}\right)$}

The $\gamma-\mathrm{Fe}_{2} \mathrm{O}_{3} / \mathrm{SiO}_{2} \mathrm{MS}$ were prepared via a modified ESE (Emulsion Solvent Evaporation) method,[37] which has already been published.[38] First, $25 \mathrm{~mL}$ of a precursor solution was prepared by adding $5 \mathrm{~mL}$ of a $0.15 \mathrm{~mol} \mathrm{~L}^{-1} \mathrm{HNO}_{3}$ aqueous solution to $20 \mathrm{~mL}$ of tetraethoxysilane (TEOS). This mixture was vigorously stirred for $45 \mathrm{~min}$. During this period, TEOS was hydrolyzed up to an adequate level to obtain a monophasic solution. Then, $40 \mathrm{~mL}$ of a magnetic sol was formed by adding $20 \mathrm{~mL}$ of the precursor solution to $20 \mathrm{~mL}$ of an aqueous dispersion of $\gamma-\mathrm{Fe}_{2} \mathrm{O}_{3} \mathrm{NP}$ (equivalent to $0.25 \mathrm{~mol} \mathrm{~L}^{-1}$ of $\mathrm{Fe}$ ) in a $10^{-2} \mathrm{~mol} \mathrm{~L}^{-1} \mathrm{HNO}_{3}$ aqueous solution. The magnetic sol was stirred during $5 \mathrm{~min}$ before being added dropwise to $360 \mathrm{~mL}$ of an organic phase composed of a vegetable oil (usually commercial rapeseed oil) containing $0.1 \% \mathrm{w} / \mathrm{w}$ of the emulsifier Arlacel P135. After $30 \mathrm{~min}$ of addition, the water-inoil emulsion thus formed was stirred during 30 min and then transferred into a Buchner flask. The flask was closed and connected to a water aspirator. The ethanol formed by hydrolysis of TEOS was thus evaporated from the dispersed phase under reduced pressure (35 $\mathrm{mm} \mathrm{Hg})$ during $35 \mathrm{~min}$. During this process, the temperature was fixed at $35^{\circ} \mathrm{C}$ by way of a water bath 
around the flask, and magnetic stirring was continuously maintained. Next, the system was brought back to atmospheric pressure and the emulsion was stirred again during one night. The emulsion was finally broken by addition of a large amount of acetone. The mixture was stirred during $5 \mathrm{~min}$ afterwards the MS beads were recovered with a magnet. They were washed several times with acetone and water, and dried at $70^{\circ} \mathrm{C}$ for $4 \mathrm{~h}$. Finally, the beads were calcined in an oven under air at $400^{\circ} \mathrm{C}$ for $18 \mathrm{~h}$ to remove any organic traces.

\subsection{Characterization methods}

Transmission electron microscopy (TEM) images of the $\gamma-\mathrm{Fe}_{2} \mathrm{O}_{3} \mathrm{NP}$ and the $\gamma-\mathrm{Fe}_{2} \mathrm{O}_{3} / \mathrm{SiO}_{2} \mathrm{MS}$ were taken using a JEM JEOL $100 \mathrm{CX}$ microscope operating at $100 \mathrm{kV}$. In this aim, the MS were embedded in a resin (AGAR 100) polymerised at $60^{\circ} \mathrm{C}$ during two days, and cut in 70 $\mathrm{nm}$ thin sections using a LEICA ULTRACUT UCT microtome apparatus. The MS were also observed by scanning electron microscopy (SEM) on a SEM-FEG Hitachi SU-70 apparatus. The images were taken in secondary electron mode with an accelerating voltage of $10 \mathrm{kV}$. Prior to analysis, the beads were coated with a thin shell of gold by sputter deposition. Energy-dispersive X-ray spectra (EDS) were obtained using the apparatus operating with an Oxford X-Max detector at an accelerating voltage of $10 \mathrm{kV}$. The size distribution of the particles was determined from TEM or SEM pictures analyzed using the ImageJ software. The amount of $\gamma-\mathrm{Fe}_{2} \mathrm{O}_{3} \mathrm{NP}$ in the MS was determined by spectrophotometry. A given weight of material was first introduced in an $\mathrm{HCl}$ aqueous solution $\left(4 \mathrm{~mol} \mathrm{~L}^{-1}\right)$. After $48 \mathrm{~h}$, the supernatant became yellow, indicating that the NP encapsulated inside the beads were dissolved under the form of an aqueous solution of $\left[\mathrm{FeCl}_{4}\right]^{-}$complex ions. Hence, the iron concentration in the supernatant was analyzed by atomic absorption spectrophotometry (Perkin Elmer AA100 apparatus) and the weight fraction of $\gamma-\mathrm{Fe}_{2} \mathrm{O}_{3}$ in the beads, $\mathrm{w}_{\mathrm{Fe} 2 \mathrm{O} 3}$ was 
determined. A similar procedure was used to determine the amount of $\gamma$ - $\mathrm{Fe}_{2} \mathrm{O}_{3} \mathrm{NP}$ dispersed in water.

Magnetic characterizations of the NP and MS samples were respectively made on a vibrating sample magnetometer (home-made apparatus) and SQUID magnetometer (Quantum Design MPM-5S apparatus). Each analysis was performed at $25^{\circ} \mathrm{C}$. The NP were analysed dispersed in water, whereas the MS were analysed in powdered form. The magnetizationdemagnetization curves, $\mathrm{M}=\mathrm{f}(\mathrm{H})$, where $\mathrm{H}$ is the external magnetic field (in Oersted, Oe), and $\mathrm{M}$ the magnetization of the sample in emu $\mathrm{g}^{-1}$, were normalized to $1 \mathrm{~g}$ of $\gamma-\mathrm{Fe}_{2} \mathrm{O}_{3}$. For the NP dispersion, $\mathrm{M}$ was originally given in $\mathrm{A} \mathrm{m}^{-1}$ and the normalization was made using the equation: $\mathrm{M}\left(\mathrm{emu} \mathrm{g}^{-1}\right.$ of $\left.\gamma-\mathrm{Fe}_{2} \mathrm{O}_{3}\right)=\mathrm{M}\left(\mathrm{A} \mathrm{m}^{-1}\right) /\left[\rho \cdot \mathrm{w}_{\mathrm{Fe} 2 \mathrm{O} 3}\right]$, where $\rho$ is the density of NP aqueous dispersion $\left(\rho=1.075 \mathrm{~g} \mathrm{~mL}^{-1}\right.$ for $\left.\mathrm{w}_{\mathrm{Fe} 2 \mathrm{O} 3}=11.2 \%\right)$. For the MS beads, the magnetization was directly given in emu $\mathrm{g}^{-1}$ of sample, and the normalization was made using the equation: $\mathrm{M}\left(\mathrm{emu} \mathrm{g}^{-1}\right.$ of $\left.\gamma-\mathrm{Fe}_{2} \mathrm{O}_{3}\right)=\mathrm{M}\left(\mathrm{emu} \mathrm{g}^{-1}\right.$ of sample $) / \mathrm{w}_{\mathrm{Fe} 2 \mathrm{O} 3}$. XRD spectra of the powdered samples were recorded using a Phillips PW 1130 diffractometer. Data were collected from $2 \theta=10^{\circ}$ to $80^{\circ}$ in $0.1^{\circ}$ steps. The diffraction peaks on the diagram were attributed to $d_{\mathrm{hk} 1}$ spacings using the Bragg equation $\mathrm{d}_{\mathrm{hk} 1}=\lambda /(2 \sin \theta)$, where $\theta$ is the Bragg angle and $\lambda$ the wavelength of the $\operatorname{CoK}_{\alpha}$ radiation $(\lambda=1.7902 \AA)$. The corresponding RX diameter of the nanocrystallites was calculated applying the Scherrer equation $\mathrm{d}=\mathrm{K} \lambda /(\Delta \theta \cos 2 \theta)$, where $\Delta \theta$ is the line broadening at half the maximum intensity of the diffraction peak, and $\mathrm{K}$ the shape factor. A value of 0.9 , typically used for spherical particles, was chosen for $\mathrm{K}$. $\mathrm{d}$ was determined as the average between the values calculated from the two main diffraction peaks corresponding to the (311) and (400) reflections. The room-temperature UV-visible-NIR spectra of the powdered samples were recorded with a diffuse reflectance cell (internal sphere) in the range 200-2500 nm on a Varian Cary 400 spectrometer (Teflon as a blank). The pure $\gamma-\mathrm{Fe}_{2} \mathrm{O}_{3} \mathrm{NP}$ were dispersed in Teflon before 
analysis. Volumetric adsorptions of nitrogen at $77 \mathrm{~K}$ and $\mathrm{CO}_{2}$ at $273 \mathrm{~K}$ were performed on a ASAP 2020 Micromeretics apparatus. Before analysis, the samples were degassed overnight at $110^{\circ} \mathrm{C}$ under high vacuum $\left(10^{-6} \mathrm{bar}\right)$.

\subsection{Catalytic Tests}

A series of Fenton's experiments was performed to measure the catalytic activity of the two materials $\left(\gamma-\mathrm{Fe}_{2} \mathrm{O}_{3} \mathrm{NP}\right.$ and $\left.\gamma-\mathrm{Fe}_{2} \mathrm{O}_{3} / \mathrm{SiO}_{2} \mathrm{MS}\right)$ for the degradation of three aqueous pollutants, methylene blue (MB), methyl orange (MO), or paranitrophenol (PNP). All the experiments were carried out in the dark at a mild temperature $\left(\mathrm{T}=40^{\circ} \mathrm{C}\right)$, in a closed vessel to avoid evaporation. In the standard tests, the following conditions were used. First, $0.3 \mathrm{~g}$ of $\gamma-\mathrm{Fe}_{2} \mathrm{O}_{3} / \mathrm{SiO}_{2} \mathrm{MS}$, or $210 \mu \mathrm{L}$ of the $\gamma-\mathrm{Fe}_{2} \mathrm{O}_{3} \mathrm{NP}$ acidic aqueous dispersion (both equivalent to $[\mathrm{Fe}]_{\mathrm{T}}=3.1510^{-2} \mathrm{~mol} \mathrm{~L}^{-1}$ in the final reaction mixture) was added to an aqueous solution of the pollutant, which $\mathrm{pH}$ was previously adjusted at 3 by addition of $\mathrm{HNO}_{3}$ (It was controlled that this $\mathrm{pH}$ value was maintained in the reaction medium for the duration of the test). The volume of this solution was chosen in a manner that the initial concentration of the pollutant in the final mixture was $\mathrm{C}_{\mathrm{i}}=2.5 \times 10^{-4} \mathrm{~mol} \mathrm{~L}^{-1}$ for a total volume of $10 \mathrm{~mL}$ (except for the MB pollutant with the MS catalyst, where $\mathrm{C}_{\mathrm{i}}$ was fixed at $8 \times 10^{-4} \mathrm{~mol} \mathrm{~L}^{-1}$ to take into account the much larger adsorption of this compound on the silica surface). The suspension containing the catalysts and the pollutant was stirred magnetically for $2 \mathrm{~h}$ to reach the adsorption equilibrium. Then, to initiate the degradation reaction, $0.68 \mathrm{~mL}$ of a $30 \% \mathrm{w} / \mathrm{w}_{2} \mathrm{O}_{2}$ aqueous solution was added to the suspension (corresponding to a concentration of $\mathrm{H}_{2} \mathrm{O}_{2}$ of $1 \mathrm{~mol} \mathrm{~L}^{-1}$ in the final mixture). The decolorization kinetic of the solution was followed by the following procedure. Solution samples were taken (typically $150 \mu \mathrm{L}$ ) at desired time intervals, and were put over a magnet to separate the supernatant from the catalysts by magnetic settlement. For the $\gamma-\mathrm{Fe}_{2} \mathrm{O}_{3} \mathrm{NP}$, a concentrated $\mathrm{KCl}$ aqueous solution $\left(50 \mathrm{~g} \mathrm{~L}^{-1}\right)$ was previously added to 
make aggregation of the nanoparticles and thus to favour their settlement. The supernatant was then recovered and diluted to an adequate concentration before to be analyzed with an UV-Visible spectrophotometer (UVIKON XL apparatus). The remaining concentration of the pollutant in the supernatant $\left(\mathrm{C}_{\mathrm{t}}\right)$ was determined using the Beer-Lambert law at 502, 400, and $665 \mathrm{~nm}$ respectively for MO, $\mathrm{PNP}$, and MB. The initial time $\mathrm{t}=0$ was fixed at the moment of adding $\mathrm{H}_{2} \mathrm{O}_{2}$. The concentration of the pollutant in the supernatant measured at $\mathrm{t}=0$ was noted $\mathrm{C}_{0}$. $\mathrm{C}_{0}$ varied from $1.8 \times 10^{-4}$ to $2.5 \times 10^{-4} \mathrm{~mol} \mathrm{~L}{ }^{-1}$, depending on the amount of adsorbed pollutant on the catalyst. The initial rate of decolorization $\left(\mathrm{v}_{0}\right)$ was determined by plotting the tangent at $\mathrm{t}=0$ of the kinetic curve $\mathrm{C}_{\mathrm{t}}=\mathrm{f}(\mathrm{t})$. The decolorization yield (DY) at $4 \mathrm{~h}$, was also evaluated from this curve, using the following formula $D Y=100-100 \cdot C_{4 h} / C_{0}$, where $\mathrm{C}_{4 \mathrm{~h}}$ and $\mathrm{C}_{0}$ are the concentrations of pollutant in the supernatant respectively at $t=0$ and $4 \mathrm{~h}$. The mineralization at $\mathrm{t}=4 \mathrm{~h}$ and $24 \mathrm{~h}$ was determined by a similar procedure analyzing the non purgeable organic carbon (NPOC) in the supernatant using a Shimadzu TOC ASI-5000A apparatus. The mineralization yield at $24 \mathrm{~h}$ (MY) was calculated with the formula $M Y=100-100 \cdot \mathrm{NPOC}_{24 h} / \mathrm{NPOC}_{0}$, where $\mathrm{NPOC}_{24 \mathrm{~h}}$ and $\mathrm{NPOC}_{0}$ are the NPOC concentrations (in $\mathrm{ppm}$ ) in the supernatant respectively at $\mathrm{t}=24 \mathrm{~h}$ and $\mathrm{t}=0$. The iron leaching was determined by measuring the iron concentrations in the supernatant at 4 hours using atomic absorption spectrophotometry. The percentage of iron leached (FeL) was calculated with the formula $F e L=100 \cdot[\mathrm{Fe}]_{s, 4 h} /[\mathrm{Fe}]_{T}$ where $[\mathrm{Fe}]_{s, 4 h}$ is the iron concentration in the supernatant at 4 hours, and $[\mathrm{Fe}]_{T}$ the equivalent iron concentration used in the catalytic test $\left([\mathrm{Fe}]_{T}=3.1510^{-2} \mathrm{~mol} \mathrm{~L}^{-1}\right)$.

The adsorption kinetics of the three aqueous pollutants on the catalysts were measured in a similar way to that of catalytic tests. The only difference was that the adsorption process was carried out without $\mathrm{H}_{2} \mathrm{O}_{2}$. The amount of $\mathrm{H}_{2} \mathrm{O}_{2}$ was replaced by an equivalent amount of the $10^{-3} \mathrm{~mol} \mathrm{~L}^{-1} \mathrm{HNO}_{3}$ aqueous solution, to maintain the $\mathrm{pH}$ level of the reaction medium at 3. 
The reuse of the $\gamma-\mathrm{Fe}_{2} \mathrm{O}_{3} / \mathrm{SiO}_{2} \mathrm{MS}$ catalyst for four times was tested using $\mathrm{MO}$ as model pollutant. The reuse tests were performed as follow. After each catalytic test (corresponding to 4 hours of reaction), the catalyst was separated from the solution by magnetic settlement, rinsed two times with $10^{-3} \mathrm{~mol} \mathrm{~L}^{-1} \mathrm{HNO}_{3}$ aqueous solution and two times with water to remove any possible contaminant from the surface. The solid was finally dried in an oven at $70^{\circ} \mathrm{C}$ overnight before the next use.

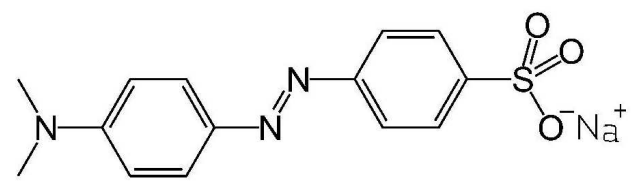

$\mathrm{MO}$<smiles>CN(C)c1ccc2nc3ccc(=[N+](C)C)cc-3sc2c1</smiles>
MB<smiles>O=[N+]([O-])c1ccc(O)cc1</smiles>

PNP

Figure 1: chemical structures of the model pollutants $(\mathrm{MO}=$ methylorange, $\mathrm{MB}=$ methylene blue, $\mathrm{PNP}=$ paranitrophenol)

\section{3- Results and Discussion}

\subsection{Synthesis and characterization of the catalytic materials}

Maghemite nanoparticles $\left(\gamma-\mathrm{Fe}_{2} \mathrm{O}_{3} \mathrm{NP}\right)$ dispersed in slightly acidic $\mathrm{HNO}_{3}$ aqueous solution, were synthesized according to the well-known Massart's method [34-36]. In brief, magnetite $\left(\mathrm{Fe}_{3} \mathrm{O}_{4}\right)$ nanoparticles were first prepared by coprecipitation of $\mathrm{Fe}^{3+}$ and $\mathrm{Fe}^{2+}$ ions in ammonia, and were then oxidized to $\gamma-\mathrm{Fe}_{2} \mathrm{O}_{3}$ by addition of $\mathrm{HNO}_{3}$ and $\mathrm{Fe}\left(\mathrm{NO}_{3}\right)_{3}$. The maghemite/silica magnetic microspheres $\left(\gamma-\mathrm{Fe}_{2} \mathrm{O}_{3} / \mathrm{SiO}_{2} \mathrm{MS}\right)$ were synthesized via a modified $\mathrm{ESE}$ (Emulsion Solvent Evaporation) procedure [37] described in our previous publication.[38] This method can be divided into five steps: (1) preparation of a magnetic sol using the acidic dispersion of $\gamma-\mathrm{Fe}_{2} \mathrm{O}_{3} \mathrm{NP}$ and a silica precursor (TEOS) previously hydrolyzed in $\mathrm{HNO}_{3}$ aqueous solution, (2) emulsification of the precursor solution in a vegetable oil containing a small amount of a hydrophobic tensioactive, (3) aging of the emulsion under vacuum allowing the shortening of 
the gel time of the silica in the sol droplets from $48 \mathrm{~h}$ to $2 \mathrm{~h}$, (4) breaking of the emulsion by addition of acetone and recovery of the MS by magnetic settlement, and (5) removal of the organic traces by washing with acetone and calcination in air at $400^{\circ} \mathrm{C}$. The choice of a vegetable oil as continuous phase of the emulsion instead of an organic solvent such as dodecane was dictated by several considerations.[38] First, vegetable oils are non toxic, inexpensive and are issued from renewable resources. Secondly, the obtained microspheres present less defaults and are smaller in comparison to those synthesized using an organic solvent. Moreover acetone, the only solvent used for washing the beads, can be easily separated from the oil and recycled. This synthesis is highly reproducible and each batch allows us to obtain more than $5 \mathrm{~g}$ of MS.

The two materials were first characterized by scanning and transmission electron microscopies (SEM and TEM). Figure 2A show a TEM image of the NP. They are polydisperse and have a rock-like morphology. Their mean diameter determined by counting the size of 100 particles is $\mathrm{d}=8.9 \mathrm{~nm}$ with a standard deviation of $2.4 \mathrm{~nm}$. These features are typical from the $\gamma-\mathrm{Fe}_{2} \mathrm{O}_{3}$ NP synthesized by the Massart's method.[39] The TEM image of a MS bead (figure 2B) shows a homogeneous and isotropic dispersion of the $\gamma-\mathrm{Fe}_{2} \mathrm{O}_{3} \mathrm{NP}$ into the silica matrix, without evidence for the formation of agglomerates or chains. Figure $2 \mathrm{C}$ shows the SEM image of the MS. As previously described,[38] the beads have a spherical shape and are polydisperse in size. They have a relatively smooth surface, although a small part of them shows defaults (small cracks or cavities). Their mean diameter determined by counting the size of more than 350 beads is $\mathrm{D}=2.0 \mu \mathrm{m}$ with a standard deviation of $1.7 \mu \mathrm{m}$. Interestingly, before calcination, the MS have the same morphology (see ESI for the SEM image), but their mean diameter is slightly larger $(D=2.3 \mu \mathrm{m})$, which may be explained by the shrinkage of the silica network by dehydration and condensation reactions at high temperature. 


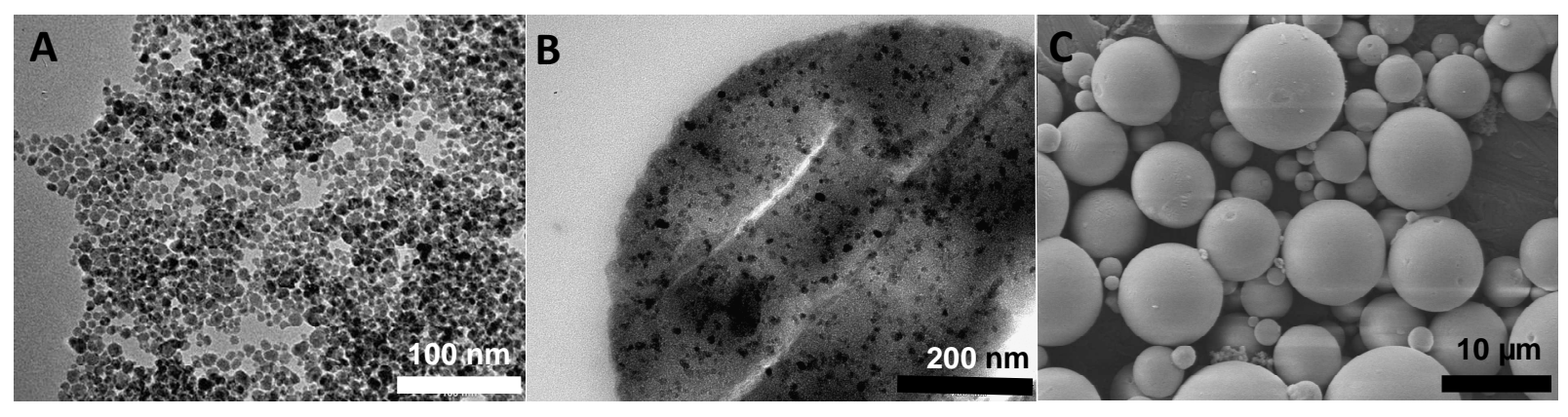

Figure 2 : (A) TEM image of the $\gamma-\mathrm{Fe}_{2} \mathrm{O}_{3} \mathrm{NP}$ (B) TEM image of a $\gamma-\mathrm{Fe}_{2} \mathrm{O}_{3} / \mathrm{SiO}_{2} \mathrm{MS}$ (C) SEM image of the $\gamma-\mathrm{Fe}_{2} \mathrm{O}_{3} / \mathrm{SiO}_{2} \mathrm{MS}$

The magnetic properties of the NP and MS were determined by magnetometry. The aqueous dispersion of the NP was studied with a vibrating sample magnetometer, whereas a more sensitive SQUID apparatus was used for the powdered MS materials. The magnetizationdemagnetization curves obtained for the samples were normalized to $1 \mathrm{~g}$ of maghemite, using the weight fractions of the $\gamma-\mathrm{Fe}_{2} \mathrm{O}_{3} \mathrm{NP}, \mathrm{w}_{\mathrm{Fe} 2 \mathrm{O} 3}$, which were previously obtained by spectrophotometry and were found equal to $11.2 \%$ and $8.1 \%$, respectively for the NP dispersed in water, and the MS beads. Both normalized curves (figure 3) are nearly superimposable and are characteristic of a superparamagnetic behaviour, with a strong magnetic susceptibility, without remanent magnetization or hysteresis. [39] This strong magnetic susceptibility is spectacularly confirmed by the behaviour of the samples in water, in presence of a magnet. Both materials are strongly attracted by the magnetic force proportional to the strong magnetic field gradient. However the very high colloidal stability of the NP in water restricts their separation from the water, on the contrary of the MS particles (see ESI for photos). The saturation magnetizations, $M_{s}$, were found equal to 62 and $66 \mathrm{emu} \mathrm{g}^{-1}$ of $\gamma-\mathrm{Fe}_{2} \mathrm{O}_{3}$, respectively for the NP and the MS samples. Both values agree well with the value usually given for $\gamma-\mathrm{Fe}_{2} \mathrm{O}_{3}$ nanoparticles $\left(\mathrm{M}_{\mathrm{s}}=60 \mathrm{emu} \mathrm{\textrm {g } ^ { - 1 }}\right)$ [39], indicating that 
the $\gamma-\mathrm{Fe}_{2} \mathrm{O}_{3} \mathrm{NP}$ were not altered, neither by their encapsulation in the silica matrix, nor by the calcination step.

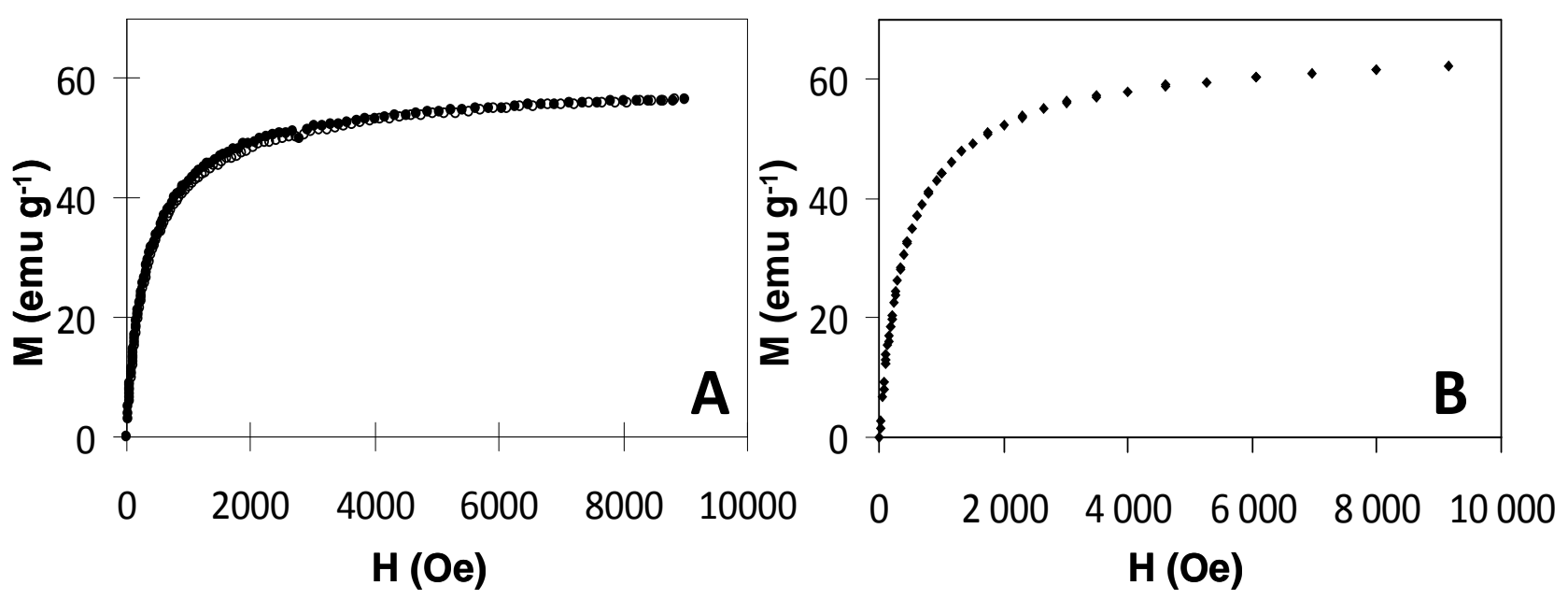

Figure 3 : Magnetization curves of (A) $\gamma-\mathrm{Fe}_{2} \mathrm{O}_{3} \mathrm{NP}$, and (B) $\gamma-\mathrm{Fe}_{2} \mathrm{O}_{3} / \mathrm{SiO}_{2} \mathrm{MS}$. The magnetization value, $\mathrm{M}$ (in emu $\mathrm{g}^{-1}$ ), is normalized to $1 \mathrm{~g}$ of $\gamma-\mathrm{Fe}_{2} \mathrm{O}_{3}$

Figure 4 shows the X-Ray Diffraction patterns and UV-Vis-NIR spectra of the $\gamma-\mathrm{Fe}_{2} \mathrm{O}_{3} \mathrm{NP}$ and $\gamma-\mathrm{Fe}_{2} \mathrm{O}_{3} / \mathrm{SiO}_{2} \mathrm{MS}$ samples. It should be noted that identical XRD and UV-Vis-NIR patterns have been obtained for the $\gamma-\mathrm{Fe}_{2} \mathrm{O}_{3} / \mathrm{SiO}_{2} \mathrm{MS}$ before calcination showing no noticeable modification of the material during the thermal treatment. In the X ray diffractograms (figure 4A), a set of sharp and relatively well-defined peaks are observed at the same angles for both samples. The corresponding distances given by the Bragg relation are 2.96, 2.50, 2.08, 1.60, and $1.46 \AA$ and can be attributed to the $\mathrm{d}_{220}, \mathrm{~d}_{311}, \mathrm{~d}_{400}, \mathrm{~d}_{511}$ and $\mathrm{d}_{440}$ interplanar spacings, which are characteristic of the crystal structure of maghemite (JCPDS 39-1346).[40] To determine the corresponding RX diameter of the nanocrystallites we used the Scherrer equation, and a diameter of $\mathrm{d}=7.1 \mathrm{~nm}$ was found for both samples, which corresponds to the diameters of the $\gamma-\mathrm{Fe}_{2} \mathrm{O}_{3} \mathrm{NP}$ obtained by TEM . In addition, the XRD pattern of the $\gamma-\mathrm{Fe}_{2} \mathrm{O}_{3} / \mathrm{SiO}_{2} \mathrm{MS}$ sample presents a very broad peak between $2 \theta=20^{\circ}$ and $40^{\circ}$ which is typical of the X-ray diffusion by amorphous silica. 
In the UV-Vis-NIR spectra (figure 4B), the absorption observed at $\lambda \geq 700 \mathrm{~nm}$ for both $\gamma$ $\mathrm{Fe}_{2} \mathrm{O}_{3} \mathrm{NP}$ and $\gamma-\mathrm{Fe}_{2} \mathrm{O}_{3} / \mathrm{SiO}_{2} \mathrm{MS}$, corresponds to electron transitions in iron oxide. At low wavelengths $(200-400 \mathrm{~nm})$, the strong absorption can be attributed to $\mathrm{O}^{2-} / \mathrm{Fe}^{3+}$ ligand to metal charge transfer transitions.[41] At larger wavelengths (400-700 nm), the absorption is also due to transitions in magnetically coupled $\mathrm{Fe}^{3+}$ cations and to crystal field "d-d" transitions in single $\mathrm{Fe}^{3+}$ cations.[41] Some of these transitions appear in the spectra as small shoulders at $480 \mathrm{~nm}$ and $650 \mathrm{~nm}$ although the observation is partially hidden by the absorption due to the charge transfer transitions. These two bands correspond respectively to the $2\left({ }^{6} \mathrm{~A}_{1}\right) \rightarrow 2\left({ }^{4} \mathrm{~T}_{1}\right)$ and ${ }^{6} \mathrm{~A}_{1} \rightarrow{ }^{4} \mathrm{~T}_{2}$ transitions and their wavelength are typical from maghemite.[41] The absorption at $\lambda \geq 700 \mathrm{~nm}$ in the precipitated $\gamma-\mathrm{Fe}_{2} \mathrm{O}_{3} \mathrm{NP}$ is larger than in the $\gamma-\mathrm{Fe}_{2} \mathrm{O}_{3} / \mathrm{SiO}_{2}$ MS, which can be explained by the larger concentration of $\gamma-\mathrm{Fe}_{2} \mathrm{O}_{3}$ in the pure NP, leading to an increase and to a collapse of the absorption bands. In the NIR part of the spectra, a very broad band is observed for $\gamma-\mathrm{Fe}_{2} \mathrm{O}_{3} \mathrm{NP}$ which can be indicative of diffusion of the aggregated nanoparticles, whereas the $\gamma-\mathrm{Fe}_{2} \mathrm{O}_{3} / \mathrm{SiO}_{2} \mathrm{MS}$ show small sharp bands at 1420,1900 , and 2250 $\mathrm{nm}$ which are assigned to overtones and combinations of the $\mathrm{OH}$ stretching vibration corresponding to silanol groups $(\mathrm{SiOH})$ and adsorbed water. [45]
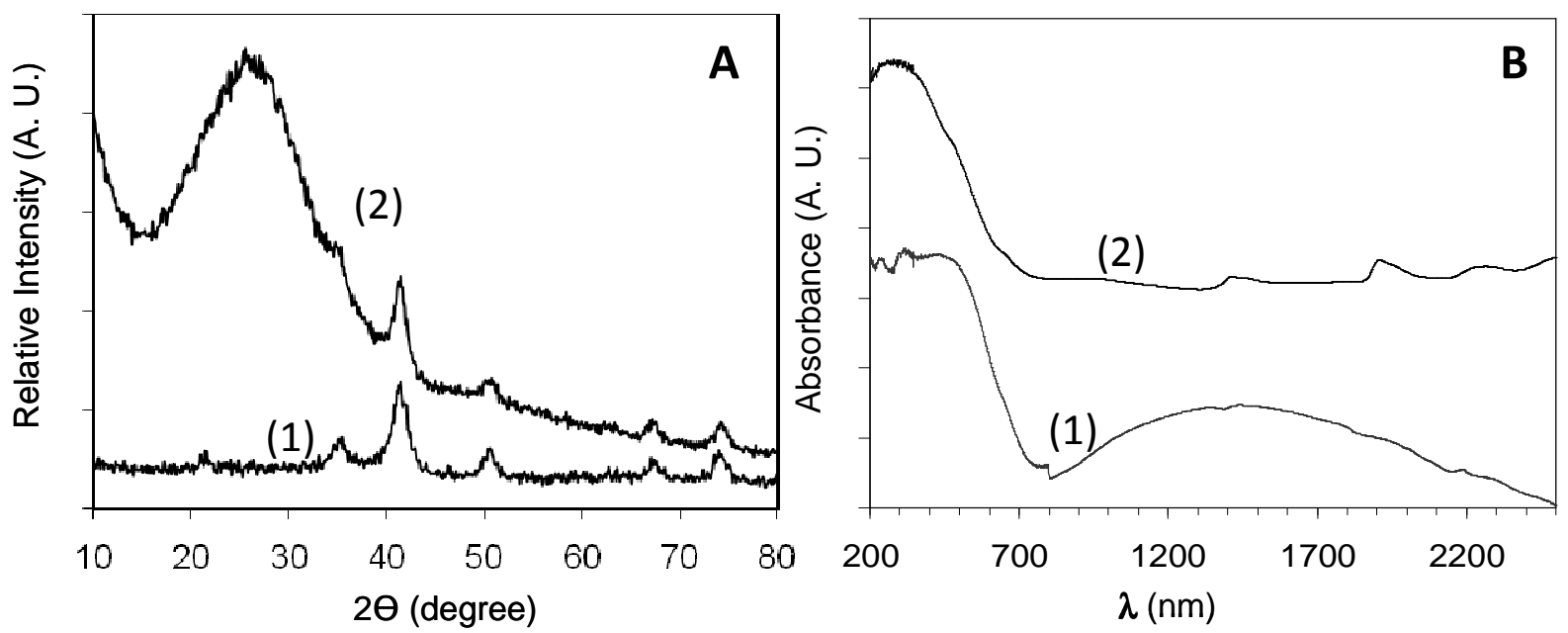

Figure 4: (A): X-Ray Diffraction patterns of (1) $\gamma-\mathrm{Fe}_{2} \mathrm{O}_{3} \mathrm{NP}$, and (2) $\gamma$ - $\mathrm{Fe}_{2} \mathrm{O}_{3} / \mathrm{SiO}_{2} \mathrm{MS}$; (B): UV-Vis-NIR spectra of (1) $\gamma-\mathrm{Fe}_{2} \mathrm{O}_{3} \mathrm{NP}$, and (2) $\gamma-\mathrm{Fe}_{2} \mathrm{O}_{3} / \mathrm{SiO}_{2} \mathrm{MS}$ 
The porosity of the materials was determined by sorption volumetry of $\mathrm{N}_{2}$ and $\mathrm{CO}_{2}$ (respectively at $77 \mathrm{~K}$ and $273 \mathrm{~K}$ ). Figure $5 \mathrm{~A}$ shows the $\mathrm{N}_{2}$ adsorption-desorption isotherms obtained for both materials. For $\gamma-\mathrm{Fe}_{2} \mathrm{O}_{3} \mathrm{NP}$, the $\mathrm{N}_{2}$ isotherm is of type II, which is observed for finely divided non-porous solids. Small amounts of $\mathrm{N}_{2}$ are progressively adsorbed on the surface of the $\gamma-\mathrm{Fe}_{2} \mathrm{O}_{3}$ NP. By applying the BET equation to the first part of the isotherm, we found that the specific surface area is $159 \mathrm{~m}^{2} \mathrm{~g}^{-1}$. This value corresponds to the theoretical external surface of spherical particles with a mean diameter of $\mathrm{d}=7.4 \mathrm{~nm} .{ }^{1}$ This implies that the BET surface area essentially corresponds to external surface and therefore that the NP are mainly non-porous. However the small hysteresis observed at $0.4<\mathrm{P} / \mathrm{P}_{0}<0.6$ in the second part of the isotherm may correspond to the condensation of $\mathrm{N}_{2}$ in a very small amount of irregular mesopores. For $\gamma-\mathrm{Fe}_{2} \mathrm{O}_{3} / \mathrm{SiO}_{2} \mathrm{MS}$, the $\mathrm{N}_{2}$ isotherm is of type I, which is characteristic of a microporous solid with pore diameters smaller than $2 \mathrm{~nm}$, and with a pore volume of $0.25 \mathrm{~mL} \mathrm{~g}^{-1}$. It should be noted that the $\mathrm{N}_{2}$ isotherm obtained for the uncalcined MS (see ESI for the isotherm), has shown the existence of larger micropores, with a larger pore volume $\left(\mathrm{V}_{\mathrm{p}}=0.38 \mathrm{~mL} \mathrm{~g}^{-1}\right)$. This indicates than partial collapse of the silica mesopores occurred during calcination. This collapse is probably related to the shrinkage of the silica matrix by condensation reactions at high temperature, which is also responsible for the small decrease of the mean diameter of the beads. The calculus of the BET surface area from the $\mathrm{N}_{2}$ isotherm being inoperative on microporous solids, $\mathrm{CO}_{2}$ adsorption volumetry was practiced on the MS. The isotherm obtained is shown in figure 5B. By modelling this isotherm with the Dubinin-Astakhov equation, which is usually well-adapted for microporous solids, [46] a surface area $(S)$ of $744 \mathrm{~m}^{2} \mathrm{~g}^{-1}$ and a microporous volume $\left(\mathrm{V}_{\mathrm{p}}\right)$ of $0.30 \mathrm{~mL} \mathrm{~g}^{-1}$ were found for the beads. These values are in accordance with the pore volume calculated from the $\mathrm{N}_{2}$ isotherm, confirming the large amount of micropores in the silica network. In addition, the

\footnotetext{
${ }^{1}$ The theoretical diameter calculated from the surface area was obtained by the relation $d=6 /\left(\rho_{\gamma-\mathrm{Fe} 2 \mathrm{O} 3} . \mathrm{S}_{\mathrm{BET}}\right)$ where $\rho_{\gamma \text {-Fe203 }}$ is the density of maghemite $\left(5.1 \mathrm{~g} \mathrm{~cm}^{-3}\right)$, and $\mathrm{S}_{\mathrm{BET}}$ the BET surface area
} 
mean diameter of the micropores, $D_{p}$, was calculated using the relation $D_{p}=4 V_{p} / S$, which is based on the hypothesis of a cylindrical geometry for the micropores. A value of $D_{p}=1.6 \mathrm{~nm}$ was found, showing that the micropores have a relatively large size, which may allow the diffusion of the pollutants into the beads.
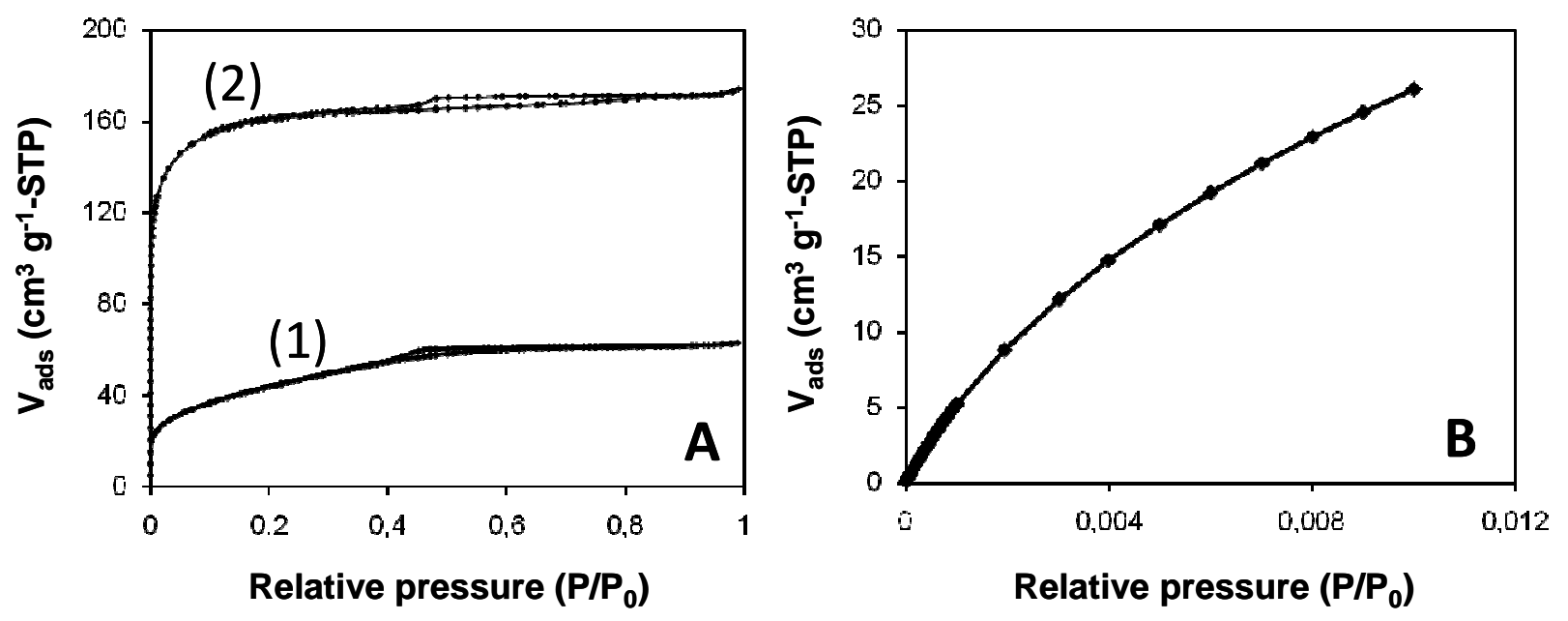

Figure 5: (A): $\mathrm{N}_{2}$ adsorption/desorption isotherms of (1) $\gamma-\mathrm{Fe}_{2} \mathrm{O}_{3} \mathrm{NP}$, and (2) $\gamma-\mathrm{Fe}_{2} \mathrm{O}_{3} / \mathrm{SiO}_{2}$ MS; (B): $\mathrm{CO}_{2}$ adsorption isotherm of $\gamma-\mathrm{Fe}_{2} \mathrm{O}_{3} / \mathrm{SiO}_{2} \mathrm{MS}$

\subsection{Catalytic Activity}

\subsubsection{Adsorption kinetics}

To control that adsorption of the three aqueous pollutants (MO, MB and PNP) on the solids does not compete with their catalytic oxidation, kinetics of their adsorption on the NP and MS catalysts were first determined. The tests were performed under the same conditions of the standard catalytic tests $\left(40^{\circ} \mathrm{C}, \mathrm{pH}=3\right.$, absence of light $)$, except that hydrogen peroxide $\left(\mathrm{H}_{2} \mathrm{O}_{2}\right)$ was not added, and the concentration of the pollutants in the supernatants was followed by UV-visible spectroscopy. The kinetic curves are presented in figure 6 . 

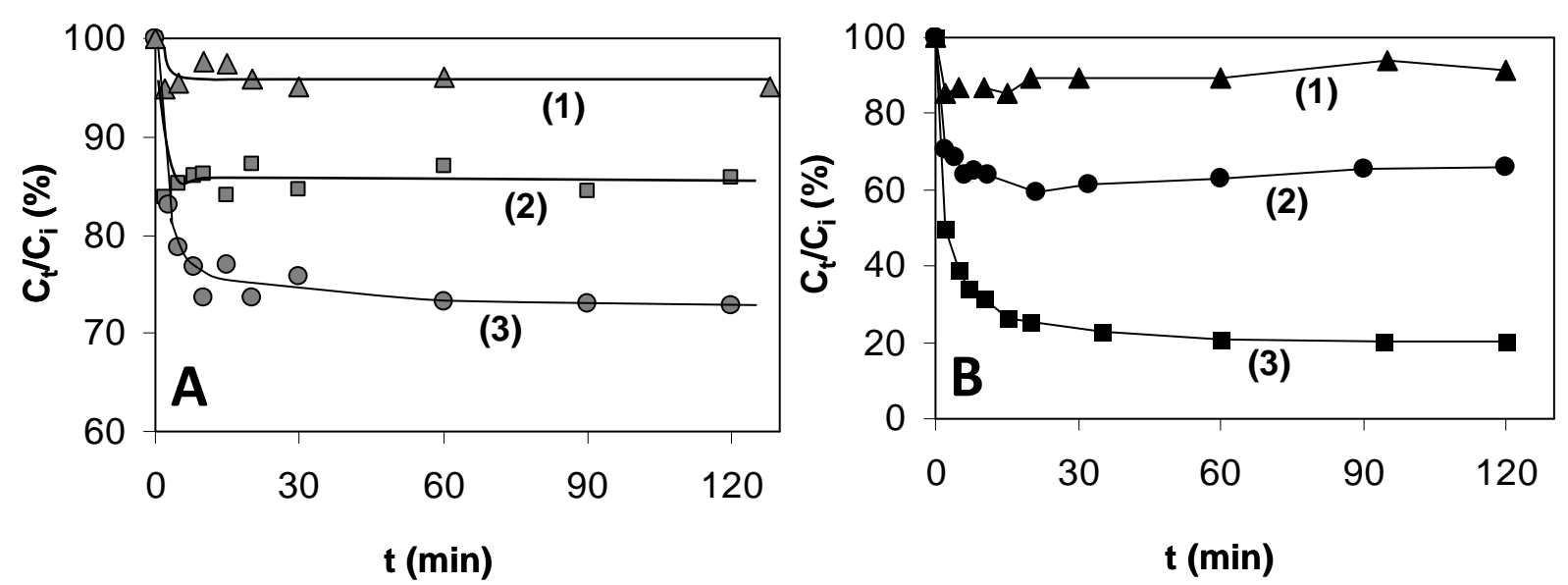

Figure 6: Adsorption kinetics of the pollutants. (A) $\gamma-\mathrm{Fe}_{2} \mathrm{O}_{3} \mathrm{NP}:(1)=\mathrm{PNP},(2)=\mathrm{MB},(3)=$ MO; (B) $\gamma-\mathrm{Fe}_{2} \mathrm{O}_{3} / \mathrm{SiO}_{2} \mathrm{MS}$ : (1) = PNP, (2) = MO, (3) $=\mathrm{MB}$. The concentration of the pollutant in the supernatant $C_{t}$ is normalized to $C_{i}$, the initial concentration of the pollutant.

For both catalysts, adsorption proceeds very quickly, and an equilibrium concentration is reached in less than $30 \mathrm{~min}$, whatever the pollutant. This shows that adsorption does not compete with the catalytic process, since $\mathrm{H}_{2} \mathrm{O}_{2}$ is added $2 \mathrm{~h}$ after the pollutants in the catalytic medium. The amounts of pollutant adsorbed at the equilibrium in ascending order are $\mathrm{PNP}<\mathrm{MB}<\mathrm{MO}$ for $\mathrm{NP}$, and $\mathrm{PNP}<\mathrm{MO}<<\mathrm{MB}$ for MS. The percentage of adsorbed pollutants ranges from less than $5 \%$ to $30 \%$, except for MB for which a very strong adsorption occurs on the MS. In this case, to obtain an equilibrium concentration comparable to that of the other tests, we had to use an initial concentration $\mathrm{C}_{\mathrm{i}}$ three times larger. However, even with this concentration, more than $80 \%$ of the pollutant remained adsorbed on the MS. Since a much smaller amount of MB was adsorbed on the free NP, this compound strongly interacts with the silica surface of the microspheres, which has already been observed for other silica based materials.[47-48] This is usually explained at $\mathrm{pH} \geq 2$ by the opposite charges of this cationic molecule and the negatively charged silica surface. ${ }^{2}$

\footnotetext{
${ }^{2} \mathrm{pH}=2$ corresponds to the point of zero charge of silica
} 


\subsubsection{Catalytic test on the three pollutants}

The three aqueous pollutants were oxidized by $\mathrm{H}_{2} \mathrm{O}_{2}$ using the NP or the MS as Fenton heterogeneous catalyst at $\mathrm{pH}=3$ and $\mathrm{T}=40^{\circ} \mathrm{C}$, in absence of light (experimental conditions of the standard tests). $\mathrm{H}_{2} \mathrm{O}_{2}$ was added $2 \mathrm{~h}$ after the adsorption of the pollutant on the catalyst $(t=0)$. The decolorization kinetics of the solutions were followed by UV-visible spectroscopy, and the possible mineralization was determined by measurement of NPOC at fixed times $(0 \mathrm{~h}$, $4 \mathrm{~h}$ and $24 \mathrm{~h}$ ). Finally the iron leaching of the catalysts was measured by analysis of the iron concentration in the supernatants after $4 \mathrm{~h}$, using atomic absorption spectroscopy. Figure 7 shows the kinetic curves obtained for the three compounds, in presence or in absence of the heterogeneous catalysts. The initial rates of decolorization $\left(\mathrm{v}_{0}\right)$, the decolorization yield (DY) at $4 \mathrm{~h}$, the mineralization yield (MY) at $24 \mathrm{~h}$, and the percentage of iron leached (FeL) at $4 \mathrm{~h}$ are reported in table 1.

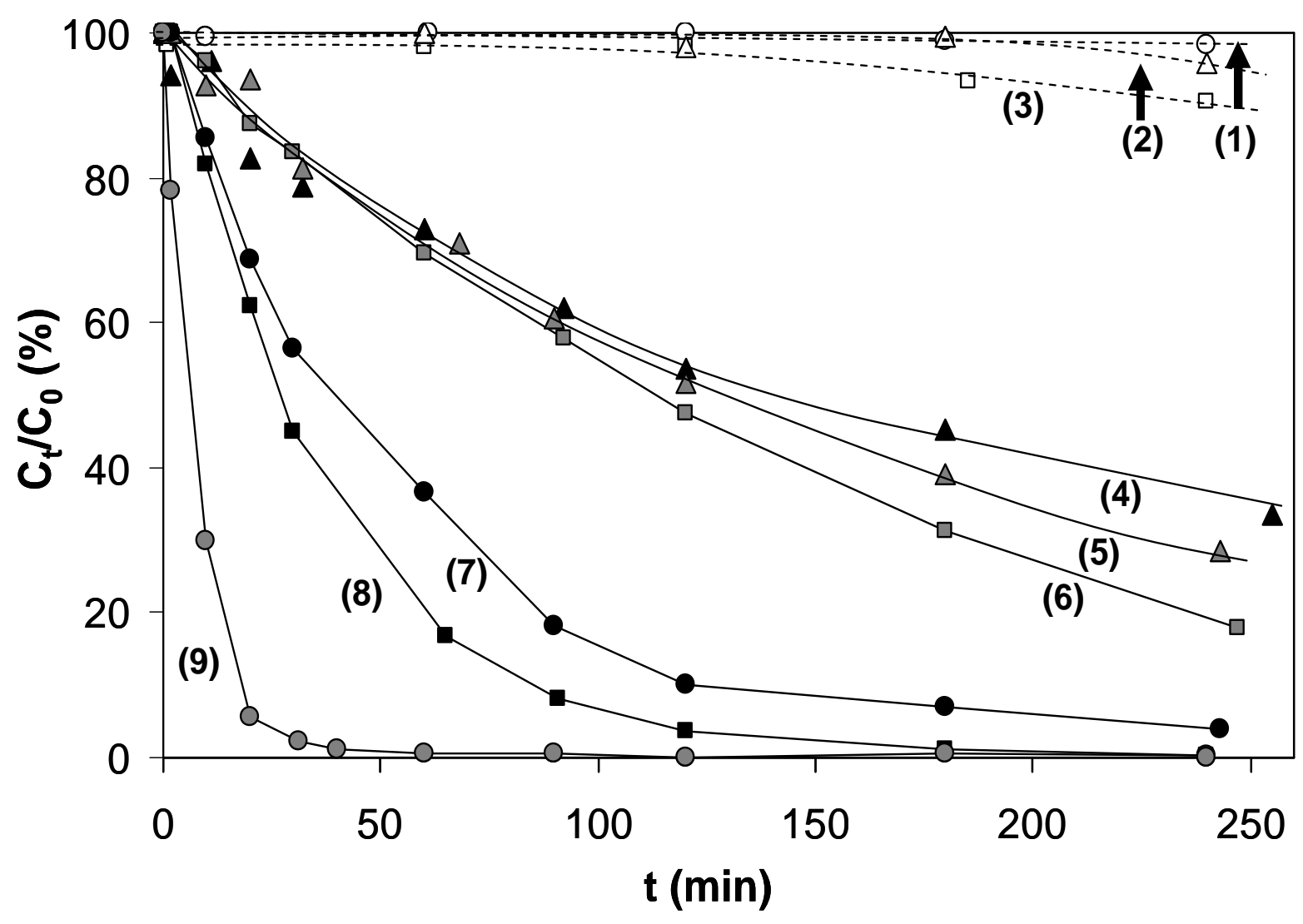


Figure 7 : Kinetic curves for the decolorization of the three pollutant solutions resulting from Fenton reactions. $(1)=\mathrm{MO}$, absence of catalyst, $(2)=\mathrm{PNP}$, absence of catalyst, $(3)=\mathrm{MB}$, absence of catalyst, (4) = PNP, MS catalyst, (5) = PNP, NP catalyst, (6) = MB, NP catalyst, (7) = MO, MS catalyst, (8) = MB, MS catalyst, (9) = MO, NP catalyst. The concentration of the pollutant in the supernatant $\mathrm{C}_{\mathrm{t}}$ is normalized to $\mathrm{C}_{0}$, the concentration of the pollutant in the supernatant at $\mathrm{t}=0$.

\begin{tabular}{|c|c|c|c|c|c|}
\hline Pollutant & Catalyst & $\begin{array}{c}\mathbf{v}_{0} \\
\left(\mu \mathrm{mol} \mathrm{L^{-1 }} \min ^{-1}\right)\end{array}$ & $\begin{array}{c}\text { DY, at } 4 \mathrm{~h}, \\
(\mathrm{~mol}, \%)\end{array}$ & $\begin{array}{l}\text { MY, at } 24 \mathrm{~h}, \\
(\text { ppm, \%) }\end{array}$ & $\begin{array}{c}\mathrm{FeL}, \text { at } 4 \mathrm{~h} \\
(\mathrm{~mol}, \%)\end{array}$ \\
\hline \multirow{3}{*}{ MO } & - & 0.03 & $1.1^{\mathrm{a}}$ & 3 & - \\
\hline & $\gamma-\mathrm{Fe}_{2} \mathrm{O}_{3} \mathrm{NP}$ & 13.3 & 99.9 & 39 & 0.26 \\
\hline & $\gamma-\mathrm{Fe}_{2} \mathrm{O}_{3} / \mathrm{SiO}_{2} \mathrm{MS}$ & 2.6 & 96.0 & 14 & 0.26 \\
\hline \multirow{3}{*}{ MB } & - & 0.08 & $9.5^{\mathrm{a}}$ & 6 & - \\
\hline & $\gamma-\mathrm{Fe}_{2} \mathrm{O}_{3} \mathrm{NP}$ & 1.1 & 82.0 & $n c^{b}$ & 0.10 \\
\hline & $\gamma-\mathrm{Fe}_{2} \mathrm{O}_{3} / \mathrm{SiO}_{2} \mathrm{MS}$ & 3.1 & 98.3 & $\mathrm{nc}^{\mathrm{b}}$ & 0.34 \\
\hline \multirow{3}{*}{ PNP } & - & 0.04 & $4.1^{\mathrm{a}}$ & 0 & - \\
\hline & $\gamma-\mathrm{Fe}_{2} \mathrm{O}_{3} \mathrm{NP}$ & 1.3 & 71.6 & 11 & 0.16 \\
\hline & $\gamma-\mathrm{Fe}_{2} \mathrm{O}_{3} / \mathrm{SiO}_{2} \mathrm{MS}$ & 1.6 & 66.8 & 27 & 0.14 \\
\hline
\end{tabular}

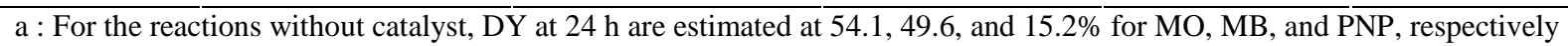
$\mathrm{b}$ : For MB, NPOC in the supernatant is increased during the catalytic tests.

Table $1: \mathrm{v}_{0}, \mathrm{DY}$ at $4 \mathrm{~h}, \mathrm{MY}$ at $24 \mathrm{~h}$, and FeL at $4 \mathrm{~h}$ for the three pollutants (MO, MB and PNP)

Both catalysts are active on the three pollutants considering the strong decolorization of the supernatants when NP or MS are added (see figure 7 and table 1). One should also mention that without catalyst, the decolorization of the solutions due to hydrogen peroxide remains negligible. The degradation of the three pollutants results in fact from the slow decomposition 
of $\mathrm{H}_{2} \mathrm{O}_{2}$ in presence of the catalysts (see ESI for the kinetic data), as it has already been evidenced with other heterogeneous Fenton catalysts.[9]. For both types of catalysts, best results are obtained with $\mathrm{MO}$, since quasi-quantitative decolorizations are attained after $4 \mathrm{~h}$ (see table 1, column 4). However, the free $\gamma-\mathrm{Fe}_{2} \mathrm{O}_{3} \mathrm{NP}$ are much more active, $\mathrm{v}_{0}$ being five times larger with this catalyst (compare in table 1, column 3, the entries 2 and 3). The lower activity of the MS material for MO can be explained by the difficulty for the reactants to access to the catalytic sites located at the surface of the $\gamma-\mathrm{Fe}_{2} \mathrm{O}_{3} \mathrm{NP}$ encapsulated in the silica beads. This hypothesis is reinforced by the kinetics results on the $\mathrm{H}_{2} \mathrm{O}_{2}$ disappearance (see ESI for data), which show that the decomposition rate of $\mathrm{H}_{2} \mathrm{O}_{2}$ with the NP catalyst is much higher than with the MS catalyst. Surprisingly, larger $\mathrm{v}_{0}$ and DY are obtained for MB with the MS catalyst, indicating that this material is more active than the free NP (compare in table 1, columns 3 and 4, the entries 5 and 6). This result may be related to the very strong adsorption of this compound on the silica surface, favouring its degradation on the neighbouring catalytic $\gamma-\mathrm{Fe}_{2} \mathrm{O}_{3}$ sites. The lowest activities are obtained with PNP, for which comparable $\mathrm{v}_{0}$ and DY are obtained with both catalysts. This fact can be explained by the enhanced chemical stability toward oxidation and/or by the weaker adsorption of this non-charged aromatic compound on the catalysts, in comparison with MO and MB. However, for each catalyst, the same tendencies are obtained for $\mathrm{v}_{0}$ (table 1) and for the amounts of adsorbed pollutant (figure 6). Therefore a larger adsorption of a pollutant on the surface of the catalyst seems to favour a better catalytic activity.

Mineralization yields of the pollutants at $4 \mathrm{~h}$ were negligible in all cases (data not given). For MO and PNP, moderate MY varying from 10 to $40 \%$ were observed only after 24 hours for both catalysts (table 1, column 5). No evidence can be given for the mineralization of MB, since the NPOC was increased between $0 \mathrm{~h}$ and $24 \mathrm{~h}$ for this compound, especially when the MS were used as catalyst. This unexpected phenomenon may be explained by the strong and 
rapid adsorption of $\mathrm{MB}$ on the catalysts, concomitant with an important desorption of the organic products resulting from the degradation of the adsorbed pollutant, these species interacting less with the catalyst surface. Therefore, despite the fast decolorization kinetics, the mineralization of the pollutants seems to proceed much more slowly. This result, which has already been observed in Fenton reactions, $[49,50]$ indicates that the pollutants are quickly oxidized into uncoloured organic molecules during the first steps of the catalytic process. These species are probably more stable toward oxidation than the parent compounds and are therefore mineralized much more slowly. For MO, our first attempts to indentify by LC-MS the organic intermediates produced during the degradation process showed that ringhydroxylated and demethylated derivatives are first formed. These compounds have already been encountered in other advanced oxidation processes.[51] Work is in progress to determine a more complete degradation pathway for the three model pollutants.

Analysis of the supernatant by Atomic Absorption Spectroscopy showed that iron leaching after 4 hours remains low, independently of the catalyst or the pollutant (table 1, column 6). In all cases, less than $0.4 \%$ of iron is leached, which corresponds to iron concentrations in the supernatant of $1.3 \times 10^{-4} \mathrm{~mol} \mathrm{~L}^{-1}$. In theses conditions, the amount of pollutant degraded by homogeneous catalysis resulting from the leached iron is probably negligible. To confirm that the catalytic process is mainly heterogeneous, two additional tests were performed on the MO pollutant. First, iron (III) nitrate with a concentration of $1.3 \times 10^{-4} \mathrm{~mol} \mathrm{~L}^{-1}$ (the maximum concentration of leached iron) was tested as homogeneous Fenton catalyst. In a second experience, we used as catalyst the supernatant obtained after $4 \mathrm{~h}$ of a catalytic test in presence of the MS. In both cases, low catalytic activities were found $\left(\mathrm{v}_{0}=0.4\right.$ and $0.6 \mu \mathrm{mol} \mathrm{L}^{-1} \mathrm{~min}^{-1}$, DY at $4 \mathrm{~h}=25.0 \%$ and $55.6 \%$, respectively for iron nitrate and the supernatant) confirming that the catalytic process is mainly heterogeneous. 


\subsubsection{Influence of experimental parameters}

To obtain a better understanding of the catalytic process, and to determine the optimal conditions for the tests, we examined the influence of several parameters on the decolorization kinetics, using MO as model pollutant. The studied parameters were the $\mathrm{pH}$, the initial concentration of $\mathrm{H}_{2} \mathrm{O}_{2}\left(\left[\mathrm{H}_{2} \mathrm{O}_{2}\right]_{0}\right)$, the amount of catalyst (expressed as $[\mathrm{Fe}]_{\mathrm{T}}$, the equivalent iron concentration), and the weight fraction of $\gamma-\mathrm{Fe}_{2} \mathrm{O}_{3} \mathrm{NP}$ in the MS beads ( $\left.\mathrm{W}_{\mathrm{Fe} 2 \mathrm{O} 3}\right)$. The results are summarized in figure 8.
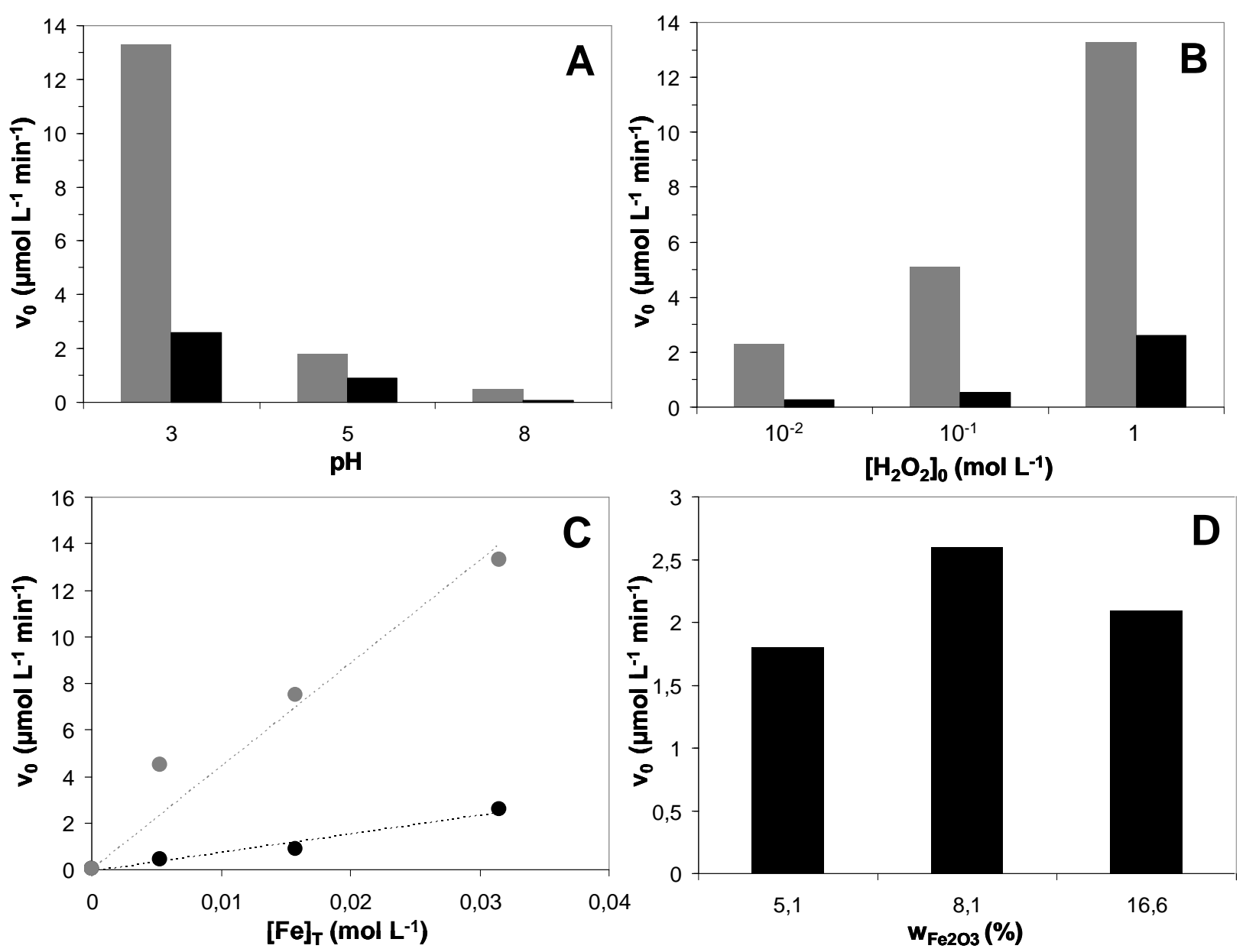

Figure 8: Influence of various parameters on the initial decolorization rate $\left(\mathrm{v}_{0}\right)$, using $\mathrm{MO}$ as model pollutant. (A) $\mathrm{pH}$; (B) initial concentration of $\mathrm{H}_{2} \mathrm{O}_{2}\left(\left[\mathrm{H}_{2} \mathrm{O}_{2}\right]_{0}\right)$; (C) amount of catalyst $\left([\mathrm{Fe}]_{\mathrm{T}}\right) ;(\mathrm{D})$ weight fraction of $\gamma-\mathrm{Fe}_{2} \mathrm{O}_{3}$ in the MS beads $\left(\mathrm{w}_{\mathrm{Fe} 2 \mathrm{O} 3}\right)$. The grey histograms and plots correspond to the NP catalyst, and the black ones to the MS catalyst. In each case, the values of the fixed parameters were the same as in the standard tests (see experimental part) 
As shown in figure $8 \mathrm{~A}$, the increase of the $\mathrm{pH}$ from 3 to 8 leads to a strong decrease of the decolorization rate. The same trends are observed for both catalysts. At pH near neutrality $(\mathrm{pH}=5)$, the catalysts are still active but $\mathrm{v}_{0}$ is lowered from 86 and $65 \%$, respectively for NP and MS catalysts. At $\mathrm{pH}=8$, the catalytic activity becomes negligible. This effect has already been encountered with other iron oxide based heterogeneous Fenton catalysts.[31] The existence of a moderate catalytic activity, allows these catalysts to be used at neutral $\mathrm{pH}$, which is not possible with Fenton homogeneous catalysts.[52] As can be seen in figure 8B, the decrease of $\left[\mathrm{H}_{2} \mathrm{O}_{2}\right]_{0}$ from $1 \mathrm{~mol} \mathrm{~L}^{-1}$ (the value used in standard tests) results in lower decolorization rates, whatever the catalyst. ( $\mathrm{v}_{0}$ is decreased by $62 \%$ and $79 \%$ at $\left[\mathrm{H}_{2} \mathrm{O}_{2}\right]_{0}=10^{-1}$ mol L ${ }^{-1}$, and by $83 \%$ and $89 \%$ at $\left[\mathrm{H}_{2} \mathrm{O}_{2}\right]_{0}=10^{-2} \mathrm{~mol} \mathrm{~L}^{-1}$, respectively for NP and MS). This observation is in agreement with works carried out on other iron oxide catalysts.[28] Indeed a lower $\mathrm{H}_{2} \mathrm{O}_{2}$ concentration implies a decrease in the production rate of $\mathrm{HO}^{\circ}$ radicals, which are responsible for the pollutant degradation. However both catalysts are still active at low $\mathrm{H}_{2} \mathrm{O}_{2}$ concentration, which has a great potential for an application in water-treatment, where a moderate amount of $\mathrm{H}_{2} \mathrm{O}_{2}$ is required for economical and technical reasons. Figure $8 \mathrm{C}$ suggests that $\mathrm{v}_{0}$ is linearly increased with the amount of catalysts. This classical result supports the idea of a true catalytic system, since it implies that the catalysts are still active at very low amount of iron $\left(\mathrm{v}_{0}\right.$ is 4.5 and $0.4 \mu \mathrm{mol} \mathrm{L}^{-1} \mathrm{~min}^{-1}$ respectively for NP and MS, at $[\mathrm{Fe}]_{\mathrm{T}}=510^{-3} \mathrm{~mol} \mathrm{~L}^{-1}$ which corresponds to a $\mathrm{H}_{2} \mathrm{O}_{2} / \mathrm{Fe}$ molar ratio of 200/1). To study the effect of the amount of $\gamma-\mathrm{Fe}_{2} \mathrm{O}_{3}$ in the MS beads, three catalysts were tested in the same conditions, each of them corresponding to a different value of $\mathrm{w}_{\mathrm{Fe} 2 \mathrm{O} 3}$. It is important to note that these catalysts have similar characteristics in term of porosity and particles size, and can be easily recovered by magnetic settlement. For the values studied, no significant influence of $\mathrm{W}_{\mathrm{Fe} 2 \mathrm{O} 3}$ on $\mathrm{v}_{0}$ was evidenced (see figure $8 \mathrm{D}$ ). This could be an indication of the absence of aggregation of the NP in the beads as their amount is increased, which would have reduced 
the accessibility to the catalytic sites for larger values of $\mathrm{w}_{\mathrm{Fe} 2 \mathrm{O} 3}$. The best result was however obtained with the medium amount of $\gamma-\mathrm{Fe}_{2} \mathrm{O}_{3}$ (which was used in the standard experiments).

\subsubsection{Reuse of the MS catalyst and characterization after five tests}

To assess the catalyst practicality in water treatment, the catalytic materials should be $(i)$ easily removed from the effluent, and (ii) reused several times without loss of activity. As already stated, an efficient solution to remove a magnetic catalyst is to use settling over a magnet or electromagnet. However our attempts to remove the $\gamma-\mathrm{Fe}_{2} \mathrm{O}_{3} \mathrm{NP}$ after the catalytic test by this method were unsuccessful, because of their high colloidal stability which also made difficult the other separation methods such as filtration or centrifugation. On the contrary, the $\gamma-\mathrm{Fe}_{2} \mathrm{O}_{3} / \mathrm{SiO}_{2} \mathrm{MS}$ were perfectly removed from the effluent after few minutes of settling over a magnet (see photo on ESI information), which led us to study their activity during five consecutive catalytic tests, and to characterize them after these tests. The reuse efficiency of the MS was tested on the decolorization of the MO solution. All the catalytic tests were carried out for $4 \mathrm{~h}$ in the same conditions. After each run, the solid powder was magnetically separated from the solution, and then rinsed with diluted $\mathrm{HNO}_{3}$ and water to remove any possible contaminant from the surface, and finally dried at $70^{\circ} \mathrm{C}$. The results of the tests are summarized in figure 9A.

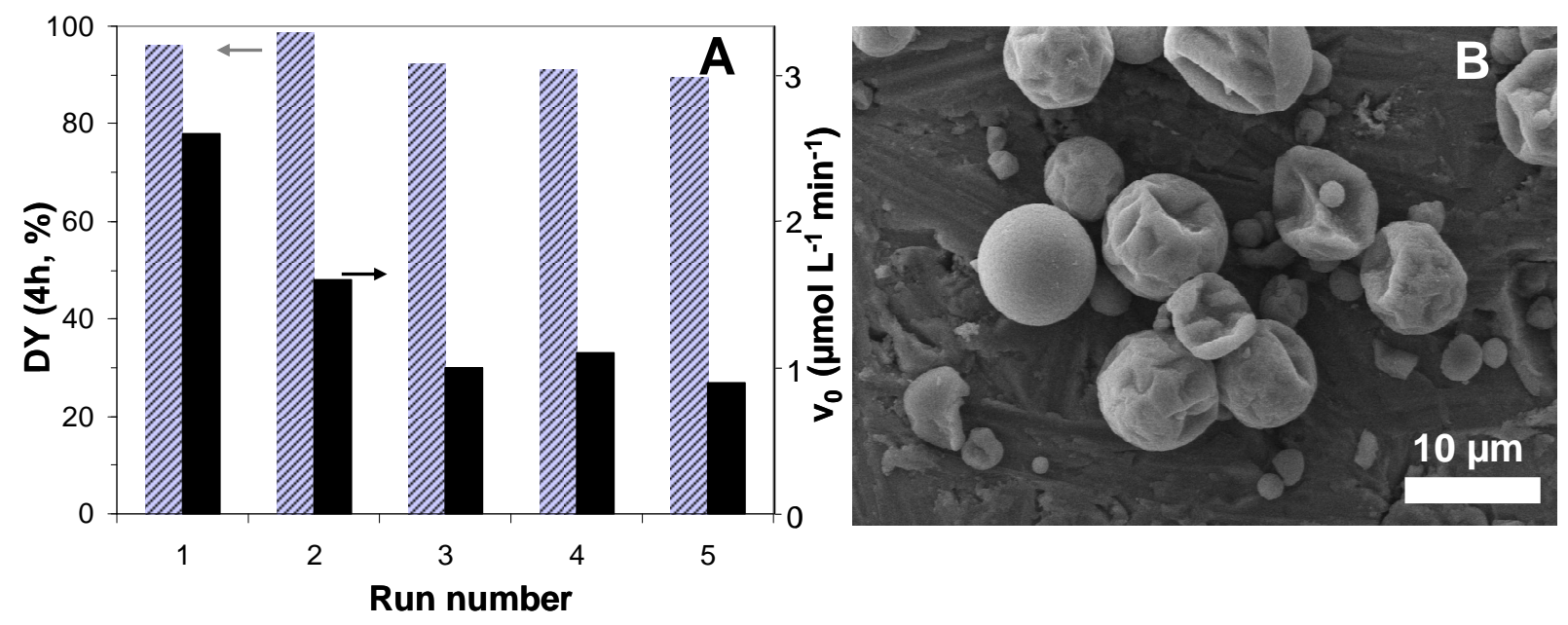


Figure $9:$ (A) $\mathrm{v}_{0}$ (black histogram, right scale), and DY at $4 \mathrm{~h}$ (hatched histogram, left scale) for five consecutive tests of the MS catalyst on the MO pollutant ; (B) SEM image of de MS catalyst after the five consecutive tests

It was observed that after five repeated experiments, the catalyst retained a good activity, despite a slight decrease in the DY at $4 \mathrm{~h}$ from $98 \%$ to $90 \%$, and a more marked decrease of $\mathrm{v}_{0}$ from 2.6 to $0.9 \mu \mathrm{mol} \mathrm{L}{ }^{-1} \min ^{-1}$ (i. e. $65 \%$ of decrease). To study the possible leaching of iron from the catalyst into the solution, the iron concentration was determined in the supernatant after each run. In all the case the percentage of leached iron remained less than $0.25 \%$, confirming the good stability of the MS catalysts (the total percentage of leached iron after five cycles is $1.2 \%$ ). It should also be noted that the slight decrease of the amount of iron in the beads is not detected by elemental analysis of the materials after the catalytic tests. In addition, the MS were characterized by several methods after the five consecutives tests. The X-Ray diffractogram, UV-Vis-NIR spectrum, and $\mathrm{N}_{2}$ adsorption isotherm were nearly identical to those before the catalytic tests (see ESI for the data), showing that the main characteristics of the material were maintained. SEM microscopy (see figure 9B) revealed that the beads kept their spherical morphology, although a slight deformation and a rougher surface were observed. This is probably due to the mechanical stress exerted on the MS beads by the stirring during the catalytic tests, and/or the drying-wetting cycles during the washing procedure. Interestingly, EDS analysis gave indications that the carbon content in the beads was increased after the tests. Therefore, to explain the moderate decrease of the catalytic activity, we propose a contamination of the MS materials by some organic intermediates remaining strongly adsorbed on the iron oxide surface. 


\section{4- Conclusion}

In this study, we have demonstrated that maghemite nanoparticles $\left(\gamma-\mathrm{Fe}_{2} \mathrm{O}_{3} \mathrm{NP}\right)$, and maghemite/silica nanocomposite microspheres $\left(\gamma-\mathrm{Fe}_{2} \mathrm{O}_{3} / \mathrm{SiO}_{2} \mathrm{MS}\right)$ can be used as heterogeneous Fenton catalysts. Both materials were characterized by TEM, SEM, magnetometry, XRD, UV-VIS-NIR spectroscopy, and sorption volumetry of $\mathrm{N}_{2}$ and $\mathrm{CO}_{2}$. The NP are non porous and have a rock-like morphology with mean diameter between 7 and 8 $\mathrm{nm}$. The MS have a polydispersed spherical shape with a mean diameter of about $2 \mu \mathrm{m}$. They are characterized by a homogeneous dispersion of the NP into a microporous silica matrix. The maghemite crystal structure of the NP is not altered by their encapsulation into the silica matrix, since no additional iron oxide phase has been detected. Therefore both catalysts exhibit a superparamagnetic behaviour with a strong magnetic susceptibility, although the strong colloidal stability of the free NP restricts their recovery by magnetic settlement. The mineralization and decolorization of aqueous solutions containing a model pollutant (MO, $\mathrm{MB}$ or PNP) in presence of the two catalysts was comparatively studied. Both catalysts are active for the three pollutants. The negligible Fe-leaching from the catalysts confirms that the degradation process is mainly heterogeneous. The rates of decolorization in ascending order are $\mathrm{PNP}<\mathrm{MB}<\mathrm{MO}$ for $\mathrm{NP}$, and $\mathrm{PNP}<\mathrm{MO}<\mathrm{MB}$ for MS. Since the same trend is found for the amounts of adsorbed pollutants, the degradation rate of the pollutant seems to be correlated to its adsorption on the catalyst. However other factors are involved to explain the difference of reactivity of the model pollutants. For the MO pollutant, the influence of the accessibility to the catalytic site seems to be predominant, whereas degradation rate of the MB pollutant is mainly influenced by its strong adsorption on the MS catalyst. . Moderate mineralization rates were observed after 24 hours for both catalysts illustrating the larger stability toward oxidation of the uncoloured organic intermediates resulting from the primary degradation of 
the pollutants. We also examined how the catalytic activity is influenced by various parameters such as the $\mathrm{pH}$, the weight fraction of $\gamma-\mathrm{Fe}_{2} \mathrm{O}_{3}$, the amount of catalyst, and the initial concentration of $\mathrm{H}_{2} \mathrm{O}_{2}$, using $\mathrm{MO}$ as model pollutant. This study has shown that the catalysts are active in a large variety of experimental conditions. The efficiency and stability of the MS catalyst was established by a study that showed that the material maintained a good activity for MO during five repeated experiments, despite a relative decrease in the reaction rates. Characterization of the MS after these tests confirmed their good stability. To improve the performances of these heterogeneous magnetic catalysts, we are now orienting our work toward the synthesis of more complex nanocomposite materials and to the activation of the catalysts by light (photo-Fenton process). In addition, a LC-MS study will be performed to determine the degradation mechanism of the three pollutants.

\section{5- References}

[1] R. P. Schwarzenbach, B. I. Escher, K. Fenner, T. B. Hofstetter, C. A. Johnson, U. Von Gunten, B. Wehrli, Science 313 (2006) 1072-1077.

[2] I. Hespanhol and R. Helmer, "Water Pollution" in: J. M. Stellman (Ed.), Encyclopaedia of occupational health and safety, Volume 2, International Labour Office, 1998, pp. 53.16-53.19

[3] S. Parsons, B. Jefferson, Introduction to potable water treatment processes, WileyBlackwell, 2006.

[4] R. Burkhart, A. Deletic, A. Craig, Urban Water 2 (2000) 197-221.

[5] G. Crini et P.M. Badot (Eds), Traitement et épuration des eaux industrielles polluées, Presses Universitaires de Franche-Comté, 2007.

[6] S. Parsons, Advanced oxidation processes for water and wastewater treatment, IWA, 2004. 
[7] E. Neyens, J. Baeyens, J. Hazard. Mater. B98 (2003) 33-50.

[8] M. Hartmann, S. Kullmann, H. Keller, J. Mater. Chem. 20 (2010) 9002-9017.

[9] S. Navalon, M. Alvaro, H. Garcia, Appl. Catal. B, 99 (2010) 1-26.

[10] A. Ni Soon, B. H. Hameed, Desalination, 269 (2011) 1-16.

[11] A. Dhakshinamoorthy, S. Navalon, M. Alvaro, H. Garcia, Chem. Sus. Chem. 5 (2012) 46-64.

[12] G. Moffat, R.A. Williams, C. Webb and R. Stirling, Miner. Eng. 7 (1994) 1039-1056.

[13] Q. Jiuhui, J. Environ. Sci. 20 (2008) 1-13.

[14] R. D. Ambashta, M. Sillanpää, J. Hazard. Mater. 180 (2010) 35-49.

[15] L. J. Graham, J. E. Atwater, G. N. Jovanovic, AIChE J. 52 (2006) 1083-1093.

[16] B. A. Bolto, T. H. Spurling, Environ. Monit. Assess. 19 (1991) 139-143.

[17] D. Beydoun, R. Amal, G. K. C. Low, S. Mc Evoy, J. Phys. Chem. B, 104 (2000) 43874396.

[18] H.-W. Chen, Y.-L. Kuo, C.-S. Chiou, S.-W. You, C.-M. Ma, C.-T. Chang, J. Hazard. Mater. 174 (2010) 795-800.

[19] L. Lei, X. Hao, X. Zhang, M. Zhou, Plasma Process. Polym. 4 (2007) 455-462.

[20] S.-H. Kong, R. J. Watts, J.-H. Choi, Chemosphere, 37 (1998) 1473-1482.

[21] R. C. C. Costa, M. De Fatima, F. Lelis, L. C. A. Oliveira, J. D. Fabris, J. D. Ardisson, R. R. V. A. Rios, C. N. Silva, R. M. Lago, Catal. Commun. 4 (2003) 525-529.

[24] R. C. Wu, J. H. Qu, Water Environ. Res. 76 (2004) 2637-2642.

[25] S. Lee, J. Oh, Y. Park, Bull. Korean Chem. Soc. 27 (2006) 489-494.

[26] R. Matta, K. Hanna, S. Chiron, Sci. Total Environ. 385 (2007) 242-251.

[27] T. Shahwan, S. Abu Sirriah, M. Nairat, E. Boyac1, A. E. Eroğlu, T. B. Scott, K. R. Hallam, Chem. Eng. J. 172 (2011) 258-266.

[28] S.-P. Sun, A. T. Lemley, J. Mol. Catal. A, 349 (2011) 71-79. 
[29] S. Shin, H. Yoon, J. Jang, Catal. Commun. 10 (2008) 178-282.

[30] T. Valdés-Solís, P. Valle-Vignón, M. Sevilla, A. B. Fuertes, J. Catal. 251 (2007) 239243.

[31] T. D. Nguyen, N. H. Phan, M. H. Do, K. T. Ngo, J. Hazard. Mater. 185 (2011) 653-661.

[32] T. Valdés-Solís, P. Valle-Vignón, S. Álvarez, G. Marbán, A. B. Fuertes, Catal. Commun. 8 (2007) 2037-2042.

[33] M. Xia, C. Chen, M. Long, C. Chen, W. Cai, B. Zhou, Micropor. Mesopor. Mat. 145 (2011) 217-223.

[34] R. Massart, Trans. Magn. MAG-17 (1981) 1247-1248.

[35] V. Cabuil, Ph.D. Thesis, defended in May 1987, University Pierre et Marie Curie.

[36] F.A. Tourinho, R. Franck, R. Massart, J. Mater. Sci. 25 (1990) 3249-3254.

[37] N. Andersson, R.W. Corkery, P. C. A. Alberius, J. Mater. Chem. 17 (2007) 2700-2705.

[38] S. Abramson, W. Safraou, B. Malezieux, V. Dupuis, S. Borensztajn, E. Briot, A. Bée, J. Colloid Interfac. Sci. 364 (2011) 324-332.

[39] J.-C. Bacri, R. Perzynski, D. Salin, V. Cabuil, R. Massart, J. Magn. Magn. Mater. 62 (1986) 36-46.

[40] E. Delahaye, V. Escax, N. El Hassan, A. Davidson, R. Aquino, V. Dupuis, R. Perzynski, Y. L. Raikher, J. Phys. Chem. B. 110 (2006) 26001-26011.

[41] J. Torrent, V. Barron, Diffuse reflectance spectroscopy of iron oxides, in: A. T. Hubbard (Ed.), Encyclopedia of Surface and Colloid Science, Marcel Dekker, New York, 2002, pp. $1438-1446$.

[42] B. Gilbert, C. Frandsen, E. R. Maxey, D. M. Sherman, Phys. Rev. B, 79 (2009) 035108. [43] A. Escobedo Morales, E. Sanchez Mora, U. Pal, Rev. Mex. Fis. S, 53 (2007) 18-22.

[44] S. K. Apte, S. D. Naik, R. S. Sonawane, B. B. Kale, J. Am. Ceram. Soc. 90 (2007) 412414. 
[45] C. C. Perry, X. Li, J. Chem. Soc. Faraday Trans. 87 (1991) 761-766.

[46] M. M. Dubinin and V.A. Astakhov, Adv. Chem.. Ser. 102 (1971) 69-85.

[47] K. Y. Ho, G. McKayand, K. L. Yeung, Langmuir 19 (2003) 3019-3024.

[48] S. Abramson, C. Meiller, P. Beaunier, V. Dupuis, L. Perrigaud, A. Bee,V. Cabuil, J.

Mater. Chem. 20 (2010) 4916-4924.

[49] J. Feng, X. Hu, P. L. Yue, Water Res. 39 (2005) 89-96.

[50] T. Liu, H. You, Q. Chen, J. Hazard. Mater. 162 (2009) 850-865.

[51] C. Baiocchi, M. C. Brussino, E. Pramauro, A. B. Prevot, L. Palmisano, G. Marci, Int. J. Mass Spectrom. 214 (2002) 247-256.

[52] J. De Laat, H. Gallard, Environ. Sci. Technol. 33 (1999) 2726-2732.

\section{Aknowledgments}

We wish to kindly thank Emmanuel Aubry, David Montero, Aude Michel, Patricia Beaunier, Isabelle Pellerin, and Melanie Cohen for their technical support, and Bernard Malezieux and Valérie Pichon for the fruitfull discussions. We equally acknowledge the scientific cooperation research program PROFAS between France and Algeria for the financial support. 